This item was submitted to Loughborough's Research Repository by the author.

Items in Figshare are protected by copyright, with all rights reserved, unless otherwise indicated.

\title{
Young people's embodied social capital and performing disability
}

PLEASE CITE THE PUBLISHED VERSION

http://dx.doi.org/10.1080/14733280903500158

PUBLISHER

(C) Taylor \& Francis (Routledge)

VERSION

AM (Accepted Manuscript)

LICENCE

CC BY-NC-ND 4.0

REPOSITORY RECORD

Holt, Louise. 2019. "Young People's Embodied Social Capital and Performing Disability". figshare. https://hdl.handle.net/2134/13088. 
This item was submitted to Loughborough's Institutional Repository (https://dspace.lboro.ac.uk/) by the author and is made available under the following Creative Commons Licence conditions.

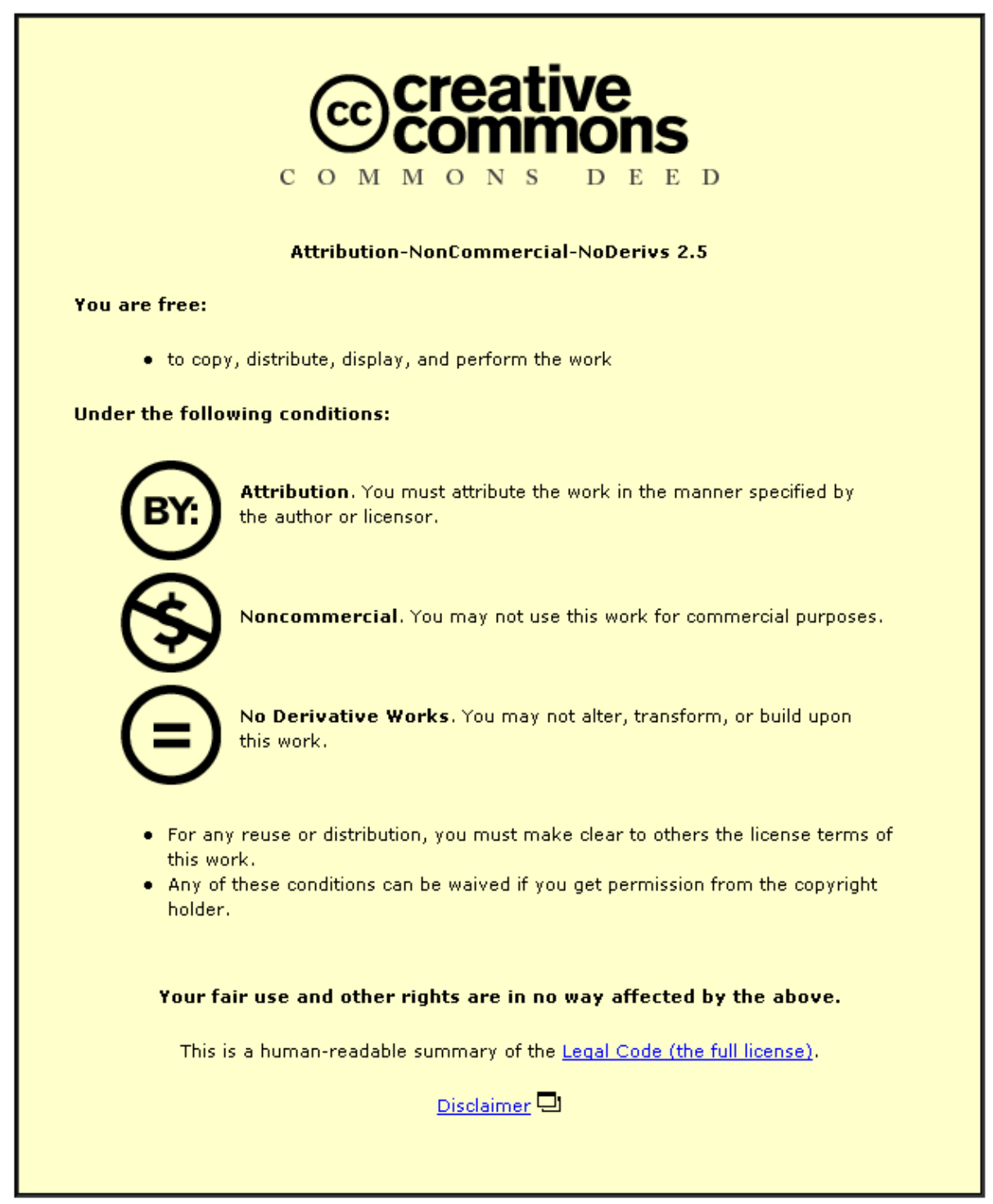

For the full text of this licence, please go to: http://creativecommons.org/licenses/by-nc-nd/2.5/ 
Children's Geographies Paper, final before Proofs

\title{
Young people's embodied social capital and performing disability
}

\begin{abstract}
This paper teases out how the identities of young people with mind-body-emotional differences are performed and constructed via their social relationships primarily within school spaces. Drawing upon the concept of embodied social capital (Holt, 2008), the paper explores empirically how young people's positioning within a variety of social networks (re)produces differentially valued identity positionings which can become embodied within young people's shifting senses of self.
\end{abstract}

\section{Introduction}

This paper examines how differentially valued embodied identities are reproduced through the social networks and relationships of young people with mind-bodyemotional differences within school spaces. The paper, as a component of this broader special edition, begins to address the marginalisation of 'disabled' young people in geography and social sciences (Davis and Watson, 2001). The absence of the voices and experiences of disabled children within the social science arena reflects and reproduces their particularly marginalised position within broader society.

When a field such as 'children's geographies' is established, an inadvertent manoeuvre of strategic essentialism takes place, which parallels that involved in the development of identity politics (Holt and Holloway, 2006). Thus, despite numerous attempts to take more account of the 'differentiations of childhood' (Matthews, 2003: 3), certain groups of young people have been marginalised within geographical accounts of children and youth. Children with mind-body differences, or 'disabled' children are one such marginalised group.

Despite the importance of a special edition such as this to countering the relative absence of disabled young people within the field, two notes of caution can also be 
Children's Geographies Paper, final before Proofs

sounded. First, that children with mind-body differences should not become a 'special interest' group. Rather, researchers could more fully take account of the way that childhood and youth intersect with a variety of axes of power within the majority of their research. Second, that some of the exclusions and marginalisations inherent with social studies and geographies of disability are not inadvertently reproduced in emerging studies of the geographies of disabled children. Clearly, perhaps, the first step towards putting young people with mind-body differences on the agenda of children's geographies is to establish a kind of 'special interest group' within a special edition, such as this. Hopefully, this special edition can influence the field more generally, such that the experiences of young people with disabilities can be explored within the various research topics of geographers and social scientists of children and youth.

In this paper, I aim to address the second note of caution. Geographies and social studies of disability can be critiqued for not taking full account of the diversity of mind-body-emotional grounds for disablement. In particular, individuals with learning disabilities and, to a lesser extent, mental ill-health have been marginalised within the field (Philo and Metzel, 2005; Parr and Butler, 1999). To date the experiences of people with socio-emotional differences have been off the radar (Holt, forthcoming a). The reasons for these marginalisations are manifold (see for instance Hall and Kearns, 2001). One particular pertinent factor is the reproduction of the mind-body dualism within social studies of disability. Critical disability researchers are members of broader society and can therefore inadvertently reproduce dominant discourses in society, such as the mind-body dualism (Parr and Butler, 1999), while simultaneously challenging others. Critical academic studies and associated political 
Children's Geographies Paper, final before Proofs

movements have endeavoured to demonstrate that individuals with bodily differences have fully functioning minds (Holt, forthcoming a). The desire to emphasise the fully functioning mind of many disabled people can be viewed as a legitimate response to dominant representations of disability which posit all disabled people as mentally incompetent (Morris, 1991). However, the adoption of this dualism further reinforces the exclusion of people with learning disabilities and/or (to a lesser extent) mental illhealth within society by marginalising such individuals and groups from debates about disability.

As a counterpoint, the young people discussed in this paper have a diversity of mindbody-emotional characteristics. All are defined as having Special Educational Needs (SEN). Some of the young people have learning disabilities and/or various bodily differences. Many of the young research participants are defined as having Social, Emotional and Behavioural Difficulties (SEBD). I use the term socio-emotional differences to express that the 'difficulties' are located within society and space at least as much as the individual characteristics of the young people (following Parr and Butler, 1999). I have argued elsewhere that young people with socio-emotional differences are often disabled via norms of appropriate behaviour and social/emotional deportment (Holt, forthcoming a). Many of the research participants have cross-cutting diagnoses and mind-body-emotional differences (see Appendix 1 for pseudonyms and some characteristics of the young people mentioned in the paper). 


\section{Embodied social capital and young people with mind-body-emotional differences}

The paper explores how differential value is accorded to the identities of young people with mind-body-emotional differences via shifting everyday practices within some of the various social networks that they construct and within which they are positioned in school spaces. How young people's (de)valued identities are embodied and materialised within their sense of self is also explored.

The concept of embodied social capital is utilised to aid conceptualisation of how differential positioning within social networks reproduces variously (de)valued embodied identities (see Holt, 2008 for a fuller discussion). Embodied social capital synthesises insights from Bourdieu's theories of capitals and habitus (e.g. Bourdieu, 1986, 1990; see also Reay, 2004a) and Butler's performativity and subjection (e.g. Butler, 1993, 1997, 2004) to theorise how everyday performances (re)produce (de)valued embodied identities which materially locate individuals; (re)producing or potentially transforming broader societal inequalities (Holt, 2008). Disability and childhood or youth, like gender, race, and so on, are (re)produced via regularly repeated everyday practices that entwine with corporeal bodies to give an illusion of natural fixity (Holt, 2007).

Crucially, the ways in which identities are performed are not fixed; they are contextual, influenced by individuals' social networks, and spatially embedded. However, once inculcated, social capital is embodied as 'habitus' and provides a context for future socio-spatial encounters. Although habitus can be transformed, its embodiment acts as a friction to change. 
Children's Geographies Paper, final before Proofs

\section{The research}

The research sought to explore how young people's embodied identities are constructed through everyday experiences of social exclusion and inclusion within school, 'home' and 'leisure' spaces. In particular, the research endeavoured to prioritise the experiences of young people (aged 11-16) with mind-body-emotional differences within wider discourses and practices of urban regeneration reproduced within a coastal town subject to sustained processes of disinvestments and decline. The research was semi-participatory, employing participatory methods to answer broad research questions established by the researcher. The methods employed were flexible and designed to be inclusive of young people with a range of mind-bodyemotional characteristics. Specific tools included repeated semi-structured focus groups and self-directed photography. The photographs were used to construct 'storyboards' that could include written text, depending upon young people's preferences (see Figure 1).

$<<$ Figure 1 about here $>>$

These storyboards and self-directed photographs were adapted from methods used by Aitken and Wingate (1993), which seek to engage with young people's ways of knowing and communicating. The storyboards served as semi-projective tools to prompt discussions with young people, and individuals were only asked to comment upon their own storyboards.

The methodology employed was flexible and circular. Although loosely structured, there was scope in focus group discussions for the young people to raise issues that 
Children's Geographies Paper, final before Proofs

most concerned them. Results of the analysis were fed back to young people within focus groups. However, given institutional constraints operating within schools and as young people could withdraw from the research at any time, this circularity was imperfect. Not all the young people were present at focus groups where feedback was presented about generalised and anonymised ongoing findings.

Given the unequal macro-scale power-relations between adults and youth, and 'nondisabled' and 'disabled people', conducting research with young people who have mind-body-emotional differences raises particular 'ethical' concerns (Alderson and Morrow, 2004; Beresford, 1997; Oliver, 1992; Kitchin, 1999; Davis et al., 2000). There is not scope in this paper to consider the ethical/methodological dimensions of the research in depth, and these will be discussed in detail elsewhere (see also Holt, 2004a). However, three key particular issues that emerged are briefly discussed here.

First, young people were recruited through schools. This recruitment strategy raises a particular set of complexities, such as negotiating gatekeepers and wider powerrelations between young people and adults within school contexts (see Holt, 2004a; Valentine, 1999). It was essential that full, written consent of both parents/guardians and young people was gained, and every effort was made to ensure that young people could consent - actively volunteer, rather than assent - agree without a clear opportunity to refuse to participate in the research (Valentine, 1999; Alderson, 1995). Clear indications of the costs to participants (in terms of time) and the limited potential benefits of participating in the research were provided in language appropriate for the young people and their parents/guardians. 
Gaining consent from parents/guardians and young people proved complex and a constraint to organising the scheduling of research activities. Some young people who were keen to be involved in the research mislaid or forgot their parental consent forms and focus groups had to be re-scheduled and reconfigured on a number of occasions. A small number of young people who claimed to be keen to participate never managed to present a completed parental/guardian consent form and were unable to participate in the research. This was ethically problematic, as the issue impacted particularly upon young people with learning differences which affect organisational skills and those with complex family and home relationships. Nonetheless, every effort was made to be flexible and give young people who wanted to participate in the research multiple opportunities to provide a signed parental/guardian consent form.

Second, and crucially, it is essential that young people are protected from harm from the research process and/or the researcher (Beresford, 1997). 'Harm' which may emerge from the social science research process is difficult to assess (Alderson and Morrow, 2004), and may be beyond the control of the researcher. Focus groups were utilised rather than individual interviews partly as they circumvent the potential problematics of interviewing young people alone. However, focus groups bring their own complexities. Individuals might express their experiences differently in a group as opposed to an individual, or self-selected paired setting. Further, focus groups are semi-ethnographic forums within which broader social relations can be (re)produced, facilitating an insight into the social relationships under investigation. Thus they provide scope for both affirmation and support, and stigmatisation and exclusion. As a focus group facilitator, I carefully constructed prompts to avoid raising issues that 
Children's Geographies Paper, final before Proofs

might make young people feel uncomfortable. However, the focus groups were not tightly structured, and I did not fully control the discussions. I did, however endeavour to steer discussions away from conversations which might cause emotional pain to young people. Intervening in potentially emotionally harmful discussions itself raises a host of ethical ambiguities; such intervention involves the employment of a (transient) hierarchical relationship between young person/adult; researched/researcher, reminiscent of a 'pseudo-therapeutic' relationship (Parr, 1998). These transient hierarchical relationships draw upon the authority with which adults are invested relative to young people in broader society.

In total eighteen young people participated in the research. Participation in the focus groups was fluid. Some young people participated in all three repeated focus groups. More often, however, individuals opted to participate in one or two focus groups. Those focus groups that at least partly reflected friendship networks facilitated enhanced continued participation by research participants.

\section{Social inclusion/exclusion and social capital: the experiences of young people with mind-body-emotional differences}

This section begins to unravel some of the complex social relationships that young people construct and sustain, within the 'everyday spaces' (James et al., 1998; Holloway and Valentine, 2000) through which their lives are mapped, lived and experienced. Particular, emphasis in this paper is placed on the context of the school. How, and whether, such relationships constitute social capital is explored. 
Children's Geographies Paper, final before Proofs

\section{Young people's school-based social networks: inclusions, exclusions, marginalisations}

\section{Bonding and bridging social capital}

Young people's 'informal' social interactions were typified by a myriad of variously inclusive or exclusive networks. These networks were not fixed; rather they shifted over space and time. Some young people constructed relatively stable social relationships with a small number of peers, while often also locating themselves within relatively transient and shifting wider social networks. For instance, Annie's storyboard had photographs of three other young people. One photograph was a picture of her and another girl; the caption read "This is me and my best friend. We were out in the rain that day" (see Figure 2). When asked about her storyboard, Annie emphasised that this was her best friend, with whom she had a supportive relationships. She also tapped into other networks, although these were more transient.

$<<$ Figure 2 about here $>>$

Other research participants tended to have extensive, loose social relationships without a more cohesive sub-grouping of close friends. The tendency to forge cohesive friendships was somewhat gendered, with more girls reporting such relationships than boys (see also Stanton-Salazar and Spina, 2005). However, some female participants exhibited more diffuse and shifting social relationships. For instance, Amy states: "I hang around with my friends ... Helen, Jason, John, Paul, 
Patrick, Shane". Amy did not suggest that she had a best or very close group of friends. By contrast, some boys expressed more exclusive and cohesive friendship networks, as typified by Andrew:

Andrew: My best friend is Edward

LH: Who's he, is he in your class?

Andrew: No, he's in the Centre normally, I think.

LH: In the Centre? What is that?

Andrew: Here.

LH: $\quad$ So this is the Centre, so what is it?

Andrew: It's like these rooms ... Yeah, [I see him at] breaks and lunch, but I don't know really what he does, because he's not in all my lessons, 'cause we chose different things. (School 1, Focus Group 3)

The relative cohesion or extensiveness of the social relationships can be seen to equate to 'bonding' or 'bridging' ties (Warren et al., 1999; Putnam, 2000). Bonding ties are those which reproduce exclusive group relationships between individuals with some shared characteristics. By contrast bridging ties are more extensive, crosscutting and uniting individuals and groups with a variety of characteristics.

Bridging ties are widely perceived to have a higher value for producing what Putnam (2000) views as the positive, communitarian impacts of social capital. On the other hand, bonding ties are regarded as reinforcing insularity within groups. Drawing (conversely) upon Bourdieu, it can be suggested that bridging ties might be more open to conversion to other forms of capital than bonding links. For instance, young people with more diffuse social networks may have access to a wider range of norms of educational participation and/or become acquainted directly or indirectly with adults with differing levels of social, economic and cultural capital. However, the potential convertibility of bridging or bonding ties to other forms of capital are clearly 
Children's Geographies Paper, final before Proofs

influenced by the wider socio-spatial and economic-political contexts of these social relationships, rather than solely by the nature of the ties (Foley and Edwards, 1999).

The relative value of 'bonding' networks might often be under-estimated. Bonding ties can provide affirmation and support (Stanton-Salazar and Spina, 2005) and emotional capital (Reay, 2004b). Such relationships facilitate young people in developing positive senses of self, and contesting negative representations by others. For instance, young people used the forum of the focus group to support participants who experience bullying:

Helen: I get bullied.

Amy: They do it because they're jealous I reckon (School 2, Focus Group 2).

The support and affirmation provided by closer social networks facilitate young people in embodying the confidence to construct wider social networks. The young people that were most vulnerable to exclusion and marginalisation were those with few social networks or with only extensive, non-cohesive social networks. Given the shifting and provisional nature of these extensive ties, young people could find themselves isolated for specific time-spaces.

\section{Bonding around a disabled identity}

Conceptualising bonding and bridging social capital as distinctive is problematic, as this differentiation depends upon a dualistic division between the similarity or dissimilarity of groups and individuals within social networks. Given bonding social capital is defined as that which exists between groups and individuals with similar characteristics (Warren et al., 1999; Putnam, 2000; Schaefer-McDaniel, 2004), its conception depends upon essentialist notions of identity which foreground (perhaps 
Children's Geographies Paper, final before Proofs

transiently) certain 'axes of power' such as class or socio-economic positioning, gender, ethnicity, race, sexuality and/or disability. This rather dualistic distinction between bonding and bridging networks is overly simplistic and denies the complexity of social relationships; all individuals are dissected by various 'axes of identity', which are punctuated by aspects of similarity, difference, recognition/identification, dis-identification and/or projection (Bondi, 2003; Butler, 2004; Sibley, 1995).

Nevertheless, some young people formed cohesive social groups with individuals who they conceptualised as sharing aspects of identity, such as gender, sexuality and disability. Self-identified disability was a key identity locator around which social groups coalesced. These groups were variously gender specific and gender inclusive. In an example of the latter, Holly and her friends are active agents who constructed sometimes transient, social groups that affirm disabled identities:

Holly: We have wheelchair races.

LH: Who do you have wheelchair races with?

Holly: The boys I said.

LH: $\quad$ And who wins?

Holly: Everyone.

Violet: And I usually run with them, don't I?

Holly: $\quad$ Yeah, if I let you. (School 1, Focus Group 1).

In this example, young people with bodily differences act as gatekeepers to the inclusion/exclusion of peers who do not have the same bodily characteristics. Here, a specific type of disability equipment, the wheelchair, which often represents negative representations of disability as dependency (Matthews and Vujakovic, 1995), becomes a valuable resource for social participation (see also Holt, 2007). Young people who lack this resource must rely on gatekeepers who use a wheelchair to allow 
them to enter the social group and the game. This interchange emphasises that young people's social networks are conflictual and often have internal hierarchies (see also Valentine, 2000). In this exert Holly holds a powerful position in relation to Violet, since Violet depends upon Holly's support for inclusion into the game. Thus, social capital must be re-conceptualised to account for the differing positions that people occupy within the social networks to which they belong (see also Holt, 2008).

Importantly, the social groups that young people constructed were formed through interconnected practices of inclusion/exclusion, engaged in by the young research participants and their peers. Many of the young people who were included in certain social networks were simultaneously excluded from membership of other social groups. Such inclusions and exclusions can be based around notions of similarity and difference. However, this underplays the ways in which difference can be constructed as an exotic and desired, along with a maligned, 'other' (Sibley, 1995). Further, friendships may be based around empathy and identification (see Bondi, 2003) or recognition (Holt, forthcoming b; Butler, 2004) rather than exclusively adhering to clearly identifiable axes of similarity and difference.

Crucially, the social networks to which young people belong are not of equal status, and are ascribed variously positive and negative labels and statuses by both members and non-members. For instance, there were more 'central' and 'marginalised' groups (see also Morse Dunkley and Panelli, 2007). Further, the social capital to which people have access is dependent both on the social networks into which they are included/excluded, and their position within such networks. 
Children's Geographies Paper, final before Proofs

Those young people whose social networks comprised of individuals that were primarily non-disabled were facilitated in challenging essentialist notions of (dis)abled identity. For instance, Peter states:

Peter: I'm classified as half and half.

LH: $\quad$ And what does that mean then?

Peter: I'm half disabled and half abled.

[TWO SPEAK]

LH: $\quad$ Sorry?

Peter: $\quad$ I play football when I'm not supposed to play football.

LH: $\quad$ Why are you not supposed to play football?

Peter: I I not classified as an able person, because of my heart.

LH: $\quad$ So you're not, you're not supposed to be football? Who says -

Peter: I'm not supposed to be playing sport - but apparently according to my other doctor it's making me healthy. So I just keep playing it, I just keep going by what the doctor who tells me I'm growing healthy. (Peter, School 2, Focus Group 1).

A key factor in his self-identification as "half and half" was Peter's (contested) ability to play football. His capacity to engage in this sport led to his critique of the diagnosis of 'disabled' or 'having Special Educational Needs' which was imposed upon him by adults' medical and institutional powers of inscription. Peter's participation in football facilitated his positioning within the more central social networks of gender exclusive groupings of males performing sports; in this context, football (Swain, 2003; Bjerrum Nielson, 2004; Cornell, 2005; Smith, 2007). His social networks primarily comprised individuals defined as 'non-disabled' by the participants, further facilitating his challenge to essentialist notions of a disabled identity. As Peter illustrates “...mostly [my friends are in my] form... people I play football with, like Johnny, Tim, Tiger and James".

Peter's ability to perform his body in normative ways facilitates his inclusion into the more centralised and valued social networks in his school, which in turn reaffirms his questioning of essentialised notions of disabled identities and allows him to value his 
Children's Geographies Paper, final before Proofs

body as "half and half". This provides a clear example of the interconnections between corporeality and social readings of bodies in reproducing socio-cultural practices and discourses of disability (e.g. Moss and Dyck, 1999, 2001; Schillmeier, 2007). Peter's positioning is influenced by what his body can do. At the same time this occurs within a socio-cultural context in which young people's social valuations are tied to normative, ableist, expectations of bodily performance. Clearly, the sociospatial practices of young people (particularly males) which place a high value on performing bodies is tied to, and serves to reproduce, broader societal norms and values about appropriate bodily performance.

\section{Exclusions and Segregations}

Targeted questions about experiences of exclusion/stigmatisation and bullying were not asked within focus groups. However, such discussions were often prompted by young people who had experienced such practices. For instance, Holly discusses her experience of being stigmatised and excluded:

Holly: Because this school's crap!

LH: $\quad$ Why is that?

Holly: Because, no because I get bullied and then no-one sorts it out and then it ends up my mum having to come to school.

LH: Who do you get bullied by?

Holly: People in my class that think it's funny to take the Mickey out of disabled people... (Holly, School 1, Focus Group 3)

The exclusion experienced by Holly, emphasises that the formation of social networks among young people is characterised by conflictual and exclusionary along with inclusive processes (see also James, 1993). Of crucial importance here is Holly's suggestion that she is excluded and stigmatised specifically because she is 'disabled' (although also she provides other explanations for her exclusion, discussed below). 
Children's Geographies Paper, final before Proofs

Holly contrasts her experiences of stigmatisation and exclusion with the generalised social bonding between the classmates in her tutorial group. The cohesiveness of her tutorial group exists despite the fact that it is adult-imposed rather than self-selected by young people; in common with the majority of socio-spatial organisations within formal space-times of schools:

'LH: $\quad$ So most people... so were you saying the people in your class get picked on ...?

Holly: No. Not in my class. They're all friends except me.' (Holly, School 1, Focus Group 3).

Thus, Holly's peers label her as an 'other' and abject her through a stigmatising and exclusionary practices (Sibley, 1995). Indeed, the social relationships within which Holly is positioned and positions herself recreates micro-scale 'maps' of 'sameness' and 'otherness' around disability that reflect previous macro institutionalised geographies typified by asylums, segregated living facilities and (most pertinently) special schools (see for instance, Gleeson and Kearns, 2001). Thus, for Holly and some other focus group participants, being educated within mainstream schools was not deconstructing boundaries between disabled and non-disabled people as envisioned by proponents of inclusive education. Some explanations for the lack of, and potentials for, a generalised transformation of disabled and non-disabled subject positioning are forwarded elsewhere (notably Holt, 2004b, 2007, forthcoming a). Crucially, Holly and her friends' exclusively 'disabled' social grouping reflected and reinforced a wider geography of sometimes transient 'disabled' spaces, found in many 'mainstream' schools (Holt, 2004b, c).

Holly actively constructs positive social relationships outside her tutorial group, almost exclusively among young people (both boys and girls) with mind-body 
differences. In doing so, Holly accepts her subject position as 'disabled' (Holly along with the majority of her peers with mind-body differences, identify themselves as 'disabled'), and forges a collective disabled identity with peers.

Some young people were excluded from mainstream social groups on the grounds that they lacked certain symbolic cultural capital, in the form of highly valued commodities. For many research participants, their inability to consume certain symbolic cultural items was underpinned relative socio-economic hardship and disadvantage. The majority of young people who participated in the research were from families were no one was employed in the paid labour market and/or were employed in routine or semi-routine occupations. Although to a degree reflective of the socio-economic positioning of the majority of students in the schools (as evidenced by Ofsted reports and interviews with head teachers), the socio-economic exclusion and marginalisation of the young disabled research participants was particularly pronounced.

Although Holly initially claims that her exclusion and stigmatisation is underpinned by her peers' negative representations of disability, it is evident that her experiences of marginalisation are also associated with her family's economic hardship. For instance, after discussing her experiences of being bullied, she continues: "They say stuff like, "Oh you get your bag from Oxfam" and I can't remember what else they say, but they say shit stuff anyway". Crucially, Holly's 'home' background is economically disadvantaged; both her parents are 'unemployed' within the paid labour market, as their work consists of caring for Holly and her siblings. Holly's myriad experiences of exclusion within school, and economic hardship outside of 
Children's Geographies Paper, final before Proofs

school, reflects a more general trend in interconnections between disability and economic disadvantage experienced by many young people with mind-bodyemotional differences, and their families (Slee, 2006). Further, these findings suggest that such broader societal experiences of socio-economic exclusion influence young people's everyday experiences of social exclusion within schools. This is then further exacerbated within the school setting as the social exclusion that Holly experiences influences the types of level of social capital to which she has access. There is clearly a need to more fully tease-out the intersections between macro- scale of socioeconomic exclusion/inclusion and the exclusions/inclusions played out by young people within schools.

The role of segregated 'disabled' spaces open to disabled youth to use in their formal and informal time was important in providing space for constructing affirmative disabled identities. An example here is the 'the Centre' in School 1 (which was essentially two interlinked classrooms with certain resources such as books) which 'disabled' children could use during either 'free' curriculum periods (few disabled young people took a full formal school timetable) and/or school leisure and lunch times (see quotation from Andrew, above). The 'Centre' is clearly also a 'disabled space' marked out within the school, which may have reinforced the 'difference', sometimes interpreted as 'otherness', ascribed to disabled young people.

This segregated space was also indicative of wider segregations within the schools. For instance in School 1, young people with disabilities were offered a variety of alternative curriculum activities which were undertaken in either full or partial replacement of a standard curriculum and GCSEs. These activities ranged from 
Children's Geographies Paper, final before Proofs

learning life skills in replacement of one or two standard subjects to taking a completely alternative curriculum, for instance by working at a farm or in a garden centre. Various 'motivational activities' were offered to those with socio-emotional and/or learning differences, such as spending 6 months working with motor bikes. In School 3, some students were offered provision within the 'Inclusion Centre' for some periods during the school day ${ }^{\mathrm{ii}}$. Such provision is enabled by wider national and local policy initiatives, notably the Education Action Zone (now Excellence Cluster) and the Children's Fund. Educational Action Zones were established in areas with high levels of socio-economic disadvantage. Importantly, as with any area-based provision, there was an issue of 'ecological fallacy'. Thus, teachers emphasised that the boundaries drawn around the Education Action Zone excluded disadvantaged youngsters residing within relatively affluent neighbourhoods.

The divergent educational pathways offered to young people with mind-bodyemotional differences have the potential to re-engage them in educational activity when they are disenfranchised from school (see below). However, they also divert young people away from standardised curriculum activities, potentially replicating the critiques levelled at many special schools for not promoting the full range of educational (and consequently employment) opportunities (Barton, 1993; Alderson and Goodey, 1998). Of specific concern here, however is how effective such nontraditional forms of education are at providing opportunity for young people to promote 'social capital'; specifically that which is transferable to other forms of capital. One potential outcome is that certain young people are diverted into 'special' educational activities which do not promote the kinds of social and cultural capital that would be easily convertible to other forms of capital. This is potentially 
Children's Geographies Paper, final before Proofs

particularly problematic within the context of the cultural capital requirements of the 'knowledge economy'. Thus, certain young people might be being educated to occupy marginalilsed spaces in the labour market. It is possible that this is further reinforced by the types of social capital reproduced within these alternative curriculum contexts, which are not readily converted to institutional cultural capital and/or economic capital. On the other hand the skills learned within alternative curricula might be more useful to the young people within the spaces of disinvestment in which they are growing up. Here, where the knowledge economy has yet to be significantly felt, opportunities within skilled manual work are a relatively highly valued alternative. The social capital reproduced within these alternative spaces of education requires further research.

Segregated spaces then, are often double-edged; simultaneously providing a safe space of affirmation and demarking the space and its occupants as different, possibly, although not inevitably, in a negative sense. Importantly, although young people are clearly agents who construct their own social relationships, they are constrained and facilitated by broader socio-spatial processes such as the opportunities and constraints offered to the construction of social relationships within and outside of school spaces.

\section{Forming affirmative social relations in the face of marginalisation: developing an}

\section{affirmative sense of self}

Adopting the subject position 'disabled' is not equivalent to accepting the negative wider societal connotations of such a label, under what is defined by Oliver (1993) as the dominant 'individual tragedy model'. Rather, through their everyday practices, Holly and her friends, in common with many of the young people who participated in 
the research, actively transformed aspects of individual tragedy models of disability. Certainly Holly does not embody the tragic, passive, dependent stereotype suggested through individual tragedy accounts (see Morris, 1991; Shakespeare, 1995), and she actively contests the negative labelling by peers:

Holly: No, they just like to take the Mickey out of me because they know that I'll retaliate and I will retaliate.

LH: What do you do? What do you do if you retaliate?

Holly: I like use my mouth back, my only weapon I've got.

LH: $\quad$ And what kinds of things do you say?

Violet: I don't think you'd like to know.

Holly: No, don't think you would. (School 1, Focus Group 3).

Crucially, the social networks that Holly constructed, both within and outside of school, provide crucial emotional support, and facilitate Holly in contesting the negative representations reproduced by the everyday practices of her classmates. On one level, wider friendships serve as a practical reinforcement for resisting and contesting the negative subject position implied by such stigmatisation (for instance, by fighting back). On another level, these social relationships serve to reaffirm a positive sense of self for the young person experiencing stigmatisation. An example of how peers can reinforce the notion that the 'problem' lies within the bullies rather than the person experiencing bullying (acting as a counterpoint to dominant adult accounts, Holt, 2004b, c; Watson et al., 1999) occurred within a focus group discussion; Andrew and Violet empathise with Holly:

Violet: That's right out of order [to bully people for being disabled].

Andrew: Yeah, that is out of order, yeah.

Violet: Which one. Is that Graham and Lucy ...? (Holly, School 1, Focus Group 3)

Violet's tone of voice here implies that she will 'take action' against the bullies (action consisting perhaps of violently 'sorting out' the perpetrators, as Violet discussed similar violent action in which she and her 'gang' engage). 
The majority of young people who participated in the research were not included within the higher status groups of their peers. However, some research participants highlighted their agency and self-selection in constructing distinctive, although marginalised, social groups. Such social relationships were often related to identity positionings that are marginalised within the wider student culture, and are based upon shared experiences of stigmatisation, marginalisation and exclusion (such as in the example above). A further example of a transient grouping was the recognition and association of girls who were either ambivalent about their sexuality or who identified as lesbian or bi-sexual.

Inclusion into alternative social networks and the reproduction of anti-school norms

The majority of young people defined as having SEBD for transgressing normative, adult defined rules of behaviour, did not experience sustained exclusion from young people's cultures. This contrasts somewhat with findings of an earlier study (Holt, 2007). The limited exclusion of young people with socio-emotional differences within young people's cultures was tied to the dominant anti-school norms reproduced by the young research group participants. These anti-school values may have been partially reflective of broader informal cultures. The research participants were skewed towards those with anti-school discourses, as some young research participants attended a special facility within School 3 for students who were at danger of being excluded in the broadest sense of the term. However, anti-school discourses and practices were dominant among young people not defined as having SEBD or as being 'disengaged', and those with pro-school values were consistently 
othered. Although many research participants emphasised the importance of gaining institutional cultural capital in the form of educational qualifications for their future career prospects, overall, young people's discourses, were anti-schooliii. As the following exert emphasises:

LH: And what do you do with [your friends]? What do you do [at lunchtime and break time (recess)]?

Violet: Walk round school .. Get up to mischief, I'm afraid ...

LH: What kind of mischief to you get up to?

Holly: Annoying teachers

Violet: Annoying all the staff (School 1, Focus Group 1).

Many young people defined as having SEBD did not experience exclusion from young people's social networks; by contrast, they were given credence for testing school rules and often had vibrant social relationships. These relationships, however, frequently consisted of 'bonding' rather than 'bridging' social capital: typified by smaller, cohesive friendships with young people who were also defined as having SEBD.

Thus, many of the young people involved in the study constructed and were positioned within social networks at school, which provided 'emotional capital' in terms of support and affirmation (Reay, 2004b). However, friendships with a limited number of peers can be typified by conflict and betrayals along with trust and reciprocity. For instance, Joe claims that he is friends with Jimmy, before going on to state that "he's a got a flat face and he's a bit of a twat, but there you go" (Joe, School 3, focus group 2).

In addition to the emotional support that social relationships may provide, they also present variable opportunities to convert social, into other forms of, capital (Bourdieu, 
1986). For the young people whose social networks are constructed around a shared anti-school discourse, the types of cultural (and perhaps ultimately economic) capital to which their social relations can be converted is limited. In particular, these social relationships are not conducive to enhancing institutional cultural capital. Rather, on occasion such social networks facilitated young people in engaging in illicit activities, including absenteeism, vandalism, drug taking and other health-risking behaviour, such as smoking, as demonstrated by discussions in focus groups and some storyboards (for instance Annie's storyboard presents people smoking, see figure 2). 'Joe says quietly "Kevin, shall we skive off the last period?"' (Joe, School 3, Focus Group 1). Later in the same focus group more open discussion about breaking school rules and engaging in 'risky' practices occurs:

LH: What about at break [recess] in school, what do you do?

Joe: $\quad$ At break time we have a fag.

$\mathrm{YW}^{\mathrm{iv}}$ : At break in school?

Joe: $\quad$ Yeah, we go out and have a fag

Kevin: Smoke crack. Not really, but I have tried it!

Tom: $\quad$ Or stay in school and have a fag, we go down behind the sport's centre, or by the playschool, for a quick snout (School 3, Focus Group 1).

Rather than assuming that the young people are deficient for their inability to accumulate institutional cultural capital via engagement in the formal aspects of schooling, it is perhaps imperative to consider why school is considered irrelevant for some young people. Attempts have been made to address this issue by providing alternative curricula (see above). Perhaps it would be pertinent to more fully destabilise the formal curriculum, based as it is on classed and ethnocentric norms (Bourdieu and Passeron, 1977; Vlachou, 1997) which can be viewed as irrelevant by many young people. 
By contrast to the experience of the majority of young people who transgressed adults' norms and expectations, some research participants were relatively excluded particularly due to their pro-school and learning ethos, and for engaging in activities that enhanced the physical school space. The experience of Andrew, who had volunteered to become an eco-warrior, a role that involved attempting to prevent other students littering and clearing up litter, is illuminating here:

Andrew: I'm an eco-warrior.

[SEVERAL SPEAK]

Holly: You're just a looser!

John: I'm a prefect I can walk around.

LH: What made you decide to do that?

Andrew: Because I didn't have anything better to do.

Violet: Yeah there is.

Holly: $\quad$ Not for Andrew.

John: Looser Andrew goes around picking up rubbish.

Holly: Does he? Are you an eco-warrior?

(School 1, focus group 2).

Andrew is ridiculed by his peers for engaging in just the kinds of voluntary activity which Putnam $(1993,2000)$ views as simultaneously being and constructing social capital. This could be problematic as there are arguably positive aspects of such communitarianism, although these do not extend to the vast claims forwarded by Putnam and his advocates (see Holt, 2008; DeFilippis, 2001; Amin, 2005).

Clearly, inclusion into the peer cultures expressed within the focus groups, and suggestive of broader informal young people's cultures, is predicated on a set of antischool discourses and practices in relation to both engagement in formal curricula activities and wider pride and volunteering within the school. Thus, the social capital that is reproduced among this group of young people has some potential negative outcomes: expressive of the 'dark side' of social capital (Putzel, 1997). However, 
Children's Geographies Paper, final before Proofs

Andrew contests dominant young people's norms, by both engaging in voluntary activities and by (re)producing pro-school norms and practices; leading to exclusion and marginalisation by his peers.

\section{Extreme exclusion and isolation}

Although the majority of young people with socio-emotional differences were included within some social networks, a small minority experienced sustained exclusion from most social groupings, and were isolated. Such young people were often also excluded and marginalised within the formal culture of the school (Holt, forthcoming a). Although the cultures reproduced by young people and adults were divergent in many respects, there were points of confluence. Young people who were seen to be emotionally immature and/or who were unable to control their emotions in ways perceived to be appropriate (and had emotional outbursts) were 'othered' within the interconnected and diverse 'formal' and 'informal' school cultures.

The experience of Lee is exemplary here. He was almost completely excluded from young people's social groups. Lee's photo storyboard is indicative of the social isolation he experienced both within and outside of school (see Figure 3).

$<<$ Figure 3 about here $>>$

Focus group discussions serve to illustrate both his level of social exclusion and some of the mechanisms of marginalisation and stigmatisation to which he was subject:

Lee: $\quad$ No, I ain't really got friends.

Aiden: Yeah, because you're always bossy. That's why (School 2 Focus Group 1) 
Lee did not elaborate upon experiences of having been bullied (an issue which his teachers highlighted), and generally did not enter into discussions that would gain further insight into his social world. However, the focus group research encounter provided evidence of the types of censure to which Lee was subject. An example is presented below:

Lee: (Speaking into the microphone) She said can she have the thing back. Oh yeah, it's still recording. She said put it on table. I am putting it on the table in five, four, three, two, one and zero.

LH: $\quad$ Thank you very much.

Aiden: Lee do you know that was a waste of tape that was?

LH: $\quad$ Okay...It's doesn't matter.

Peter: Because Lee is a bit of an idiot.

Amy: $\quad$ Lee, you moron! (School 2, Focus Group 1)

It was evident that Lee frequently contravened young people's expectations of social participation during research encounters. Lee also fell outside of adults' normative expectations of social and emotional expression, resulting in being defined as having 'SEBD'. Lee was defined by his teachers as being emotionally and socially 'immature'. Young people were particularly intolerant of those with emotional and social differences typified by forms of expression that do not match age-related expectations.

In common with wider research findings (Watson et al., 1999), Lee's teachers explicitly cited Lee's personal characteristics as the cause of his peer group social exclusion. Although reflective about wider social process beyond the school (specifically within the family) in contributing to Lee's social and emotional differences, teachers were uncritical of the behavioural norms and expectations reproduced by adults and young people within the school. Thus, Lee was disabled by 
Children's Geographies Paper, final before Proofs

contrast to norms of behaviour and social participation reproduced both by his peers and adults within the school (Holt, forthcoming a). Ultimately, the exclusion that Lee experienced limited his ability to co-construct social capital.

\section{Conclusion}

In this paper, I have explored how the social networks within which young people with mind-body-emotional differences are included reproduce embodied social capital. The social networks and relationships which young people construct and within which they are positioned reproduce variously (de)valued identity positionings which can be embodied within a shifting sense of self. Focusing upon the social experiences of young people with mind-body-emotional differences has led to questioning certain conceptualisations of social capital. For instance, it has been highlighted that the hierarchical dualism between bonding and bridging social capital is problematic. It has also been suggested that young people's position within social networks is as important as the social networks to which they have access. Some thoughts have been expressed about how readily the social capital reproduced by young people can be converted into other forms of capital (notably cultural, but ultimately, perhaps economic) and how young people's social relationships can reproduce and transform broader patterns of inequality. Crucial here is not only the types of social relationships but also the socio-spatial contexts within which the social networks are reproduced. Thinking through the differential value accorded to embodied identities within social relationships and the various opportunities to convert social to other types of capital begins to raise questions about how young people's everyday socio-spatial practices reproduce and can transform broader social inequalities, establishing a 
Children's Geographies Paper, final before Proofs

research agenda to explore interconnected macro- and micro- processes of inclusion/exclusion.

\section{References}

AITKEN, S.C. \& WINGATE, J. (1993) 'A preliminary study of the self-directed photography of middle-class, homeless, and mobility-impaired children', Professional Geographer, 45, pp. 62-72

ALDERSON, P. \& GOODEY, C. (1998) Enabling Education: Experiences in Special and Ordinary Schools (London, Tufnell Press)

ALDERSON, P. \& MORROW, V. (2004) Ethics, Social Research and Consulting with Children and Young People (Barkingside, Barnardos)

ALDERSON, P. (1995) Listening to Children: Children, Ethics and Social Research, (Barkingside, Barnardos).

AMIN, A. (2005) Local community on trail, Economy \& Society, 34, pp. 612-33.

BARTON, L. (1993) Segregated special education, some critical observations, in: G. ZARB (ed.) Removing Disabling Barriers (London, Policy Studies Institute)

BERESFORD, B. (1997) Personal Accounts: Involving Disabled Children in Research (London, Social Policy Research Unit)

BJERRUM NIELSEN, H. (2004) European gender lessons: girls and boys at scout camps in Denmark, Portugal, Russia and Slovakia, Childhood, 11, pp. 207-26 
Children's Geographies Paper, final before Proofs

BONDI, L. (2003) Empathy and identification: conceptual resources for feminist fieldwork, $A C M E$, 2, pp. 65-76

BOURDIEU, P. \& PASSERON, J.C. (1977) Reproduction in Culture, Society and Education (La Reproduction) (Cambridge, Polity Press) Translated by Nice, R. BOURDIEU, P. (1986) The forms of capital, in: J.G. RICHARDSON (ed) Handbook of Theory and Research in the Sociology of Education (New York, Greenwald Press)

BOURDIEU, P. (1990) The Logic of Practice (Cambridge, Polity Press) Translated by Nice, $R$.

BUTLER, J. (1990) Gender Trouble: Feminism and the Subversion of Identity (London/New York, Routledge)

BUTLER, J. (1993) Bodies That Matter: on the Discursive Limits of 'Sex' (London/New York, Routledge)

BUTLER, J. (1997) The Psychic Life of Power: Theories in Subjection (Stanford, Stanford University Press)

BUTLER, J. (2004) Undoing gender (London/New York: Routledge).

CHRISTENSEN \& A. JAMES (eds) Research with Children: Perspectives and Practices (London, Falmer).

CORNELL, R.W. (2005) Masculinities (Cambridge, UK, Wiley-Blackwell)

DAVIS, J.M. \& WATSON, D. (2001) Where are the children's experiences? Cultural and social exclusion in 'special' and 'mainstream' schools, Disability \& Society, 16, pp. 671-687

DAVIS, J.M., WATSON, N. \& CUNNINGHAM-BURLEY, S. (2000) Learning the lives of disabled children: developing a reflexive approach, in: P. 
Children's Geographies Paper, final before Proofs

DEFILIPPIS, J. (2001) The myth of social capital in community development, Housing Policy Development, 12, pp. 781-806

FOLEY, M.W. \& EDWARDS, B. (1999) Is it time to disinvest in social capital? Journal of Public Policy, 19, pp. 199-231

GLEESON, B. \& KEARNS, R. (2001) Remoralising landscapes of care, Environment \& Planning D: Society \& Space, 19, pp. 61-80.

HALL, E. \& KEARNS, R. (2001) Making space for the 'intellectual' in geographies of disability, Health \& Place, 7, 237-246.

HOLLOWAY, S.L. \& VALENTINE, G. (2000) Spatiality and the new social studies of childhood, Sociology, 34, pp. 763-783.

HOLT, L. \& HOLLOWAY, S.L. (2006) Editorial: theorising other childhoods in a globalised world, Children's Geographies, 4, pp. 135-142

HOLT, L. (2004a) Children with mind-body differences: performing (dis)ability in primary schools classrooms, Children's Geographies, 2, pp. 219-36

HOLT, L. (2004b) Childhood disability and ability: (Dis)ableist geographies of mainstream primary schools, Disability Studies Quarterly 24, unpaginated

HOLT, L. (2004c) The 'voices' of children: de-centring empowering research relations, Children's Geographies, 2, pp. 13-27

HOLT, L. (2007) Children's socio-spatial (re)production of disability in primary school playgrounds, Environment \& Planning D: Society \& Space, 25, pp. 783802

HOLT, L. (2008) Embodied social capital and geographic perspectives, Progress in Human Geography, 32, 2, pp. 223-242 
Children's Geographies Paper, final before Proofs

HOLT, L. (forthcoming a.) Young people with socio-emotional differences: theorising disability and destabilising socio-emotional norms, Disability \& Society

HOLT, L. (forthcoming b.) Embodying and destabilising disability and childhood in: K. HÖRSCHELMANN \& R. COLLS (eds) Contested Bodies of Childhood and Youth (Parlgrave)

JAMES, A. (1993) Childhood Identities (Edinburgh, Edinburgh University Press)

JAMES, A., JENKS, C. \& PROUT, A (1998) Theorising Childhood (Cambridge, Polity Press)

KITCHIN, R. (1999) Morals and ethics in geographical studies of disability, in: J. PROCTOR, \& D. SMITH (eds) Geography and Ethics: Journeys Through a Moral Terrain, (London, Routledge).

MATTHEWS, H. (2003) Inaugural Editorial: Coming of Age for Children's Geographies', Children's Geographies, 1, pp. 3-5.

MATTHEWS, M.H. \& VUJAKOVIC, P. (1995) Private worlds and public places: mapping the environmental values of wheelchair users, Environment \& Planning A, 27, pp.1069-1083

MORRIS, J. (1991) Pride Against Prejudice: Transforming Attitudes to Disability, (London, The Women's Press).

MORSE-DUNKLEY, C. \& PANELLI, R. (2007) 'Preppy-jocks,' 'Rednecks', 'Stoners,' and 'Scum': Power and Youth Social Groups in Rural Vermont in: R. PANELLI, S. PUNCH, E. ROBSON (Eds) Young Rural Lives: Global Perspectives on Rural Childhood and Youth (London, Routledge)

MOSS, P. \& DYCK, I. (1999) Body, corporeal space and legitimating chronic illness: women diagnosed with ME, Antipode, 31, 372-397 
Children's Geographies Paper, final before Proofs

MOSS, P. \& DYCK, I. (2001) Material bodies precariously positioned: working women diagnosed with chronic illness, in: DYCK, I. DAVIS, N. LEWIS, S. \& MCLAFFERTY, S. (eds), Geographies of Women's Health, London, Routledge, pp. $231-147$

OLIVER, M. (1992) Changing the social relations of research production, Disability, Handicap \& Society, 7, pp. 101-114.

PARR, H. \& BULTER, R. (1999) New geographies of illness, impairment and disability', in: R. BULTER \& H. PARR (Eds) (1999) Mind and Body Spaces: geographies of illness, impairment and disability (London, Routledge)

PARR, H. (1998) The politics of methodology in 'post-medical geography': mental health research and the interview, Health \& Place, 4, pp. 341-353

PHILO, C. \& METZEL, D. (2005) Introduction to theme section on geographies of intellectual disability: 'outside the participatory mainstream?' Health and Place, 11, pp. $77-85$

PUTNAM, R. (2000) Bowling Alone, the Collapse and Revival of American Community (New York, Simon \& Schust).

PYER, M. (2007) The Difference that Difference Makes: Play, Space and Teenage Wheelchair Users. Paper presented at the RGS-IBG Annual International Conference London, August 2007.

REAY, D. (2004a) It's all becoming a habitus': beyond the habitual use of habitus in educational research, British Journal of Sociology of Education, 25, pp. 421-444

REAY, D. (2004b) Gendering Boudieu's concept of capitals? Emotional capital, women and social class, Sociological Review, 52, pp. 57-74

SCHAEFER-MCDANIEL, N.J. (2004) Conceptualizing social capital among young people: toward a new theory, Children, Youth \& Environments, 14, pp.153-72 
Children's Geographies Paper, final before Proofs

SCHILLMEIER, M. (2007) 'Dis/abling spaces of calculation: blindness and money in everyday life', Environment \& Planning D: Society \& Space , 25, 594-609

SIBLEY, D. (1995) Geographies of Exclusion: Society and Difference in the West, (London, Routledge).

SLEE, R. (2007) Limits to and possibilities for educational reform, Journal of Inclusive Education, 10, pp. 101-10

SMITH, J. (2007) 'Ye've got to 'ave balls to play this game sir!' Boys, peers and fears: the negative influence of school-based 'cultural accomplices' in constructing hegemonic masculinities, Gender \& Education, 19, pp. 179-198

STANTON-SALAZAR, R. \& SPINA, S. (2005) Adolescent peer networks as a context for social and emotional support, Youth \& Society, 36, pp. 379-417

SWAIN, J. (2003) How Young Schoolboys Become Somebody: the role of the body in the construction of masculinity, British Journal of Sociology of Education, 24, pp. $299-314$

VALENTINE, G. (1999b) 'Being Seen and Heard? The ethical complexities of working with children and young people at home and at school', Ethics, Place \& Environment, 2, pp. 141-155.

VLACHOU, A.D. (1997) Struggles for Inclusive Education (Buckingham, Open University Press).

WARREN, M. R., THOMPSON, J.P. \& SAEGERT, S. (1999) Social Capital and Poor Communities: A Framework for Analysis. Paper presented at the conference on Social Capital and Poor Communities: Building and Using Social Assets to Combat Poverty. New York City, February.

WATSON, N., SHAKESPEARE, T., CUNNINGHAM-BURLEY, S., BARNES, C., CORKER, M., DAVIS, J., \& PRIESTLEY, M. (1999) Life as a Disabled Child: 
Children's Geographies Paper, final before Proofs

A Qualitative Study of Young Disabled People's Perspectives and Experiences (Project report, University of Leeds) 
Children's Geographies Paper, final before Proofs

Figure 1 - An Example of a Storyboard

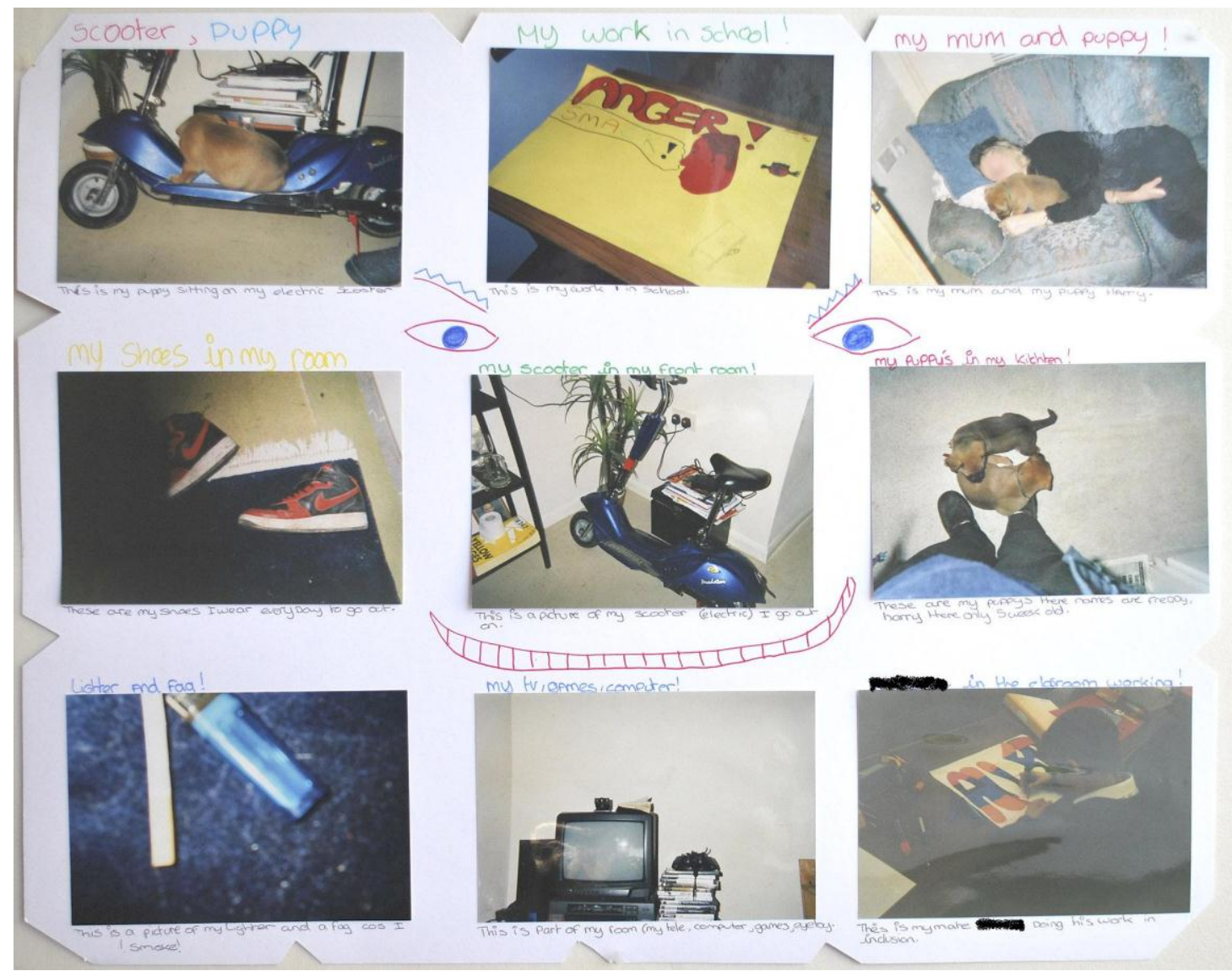

Figure 2 - Annie's Storyboard

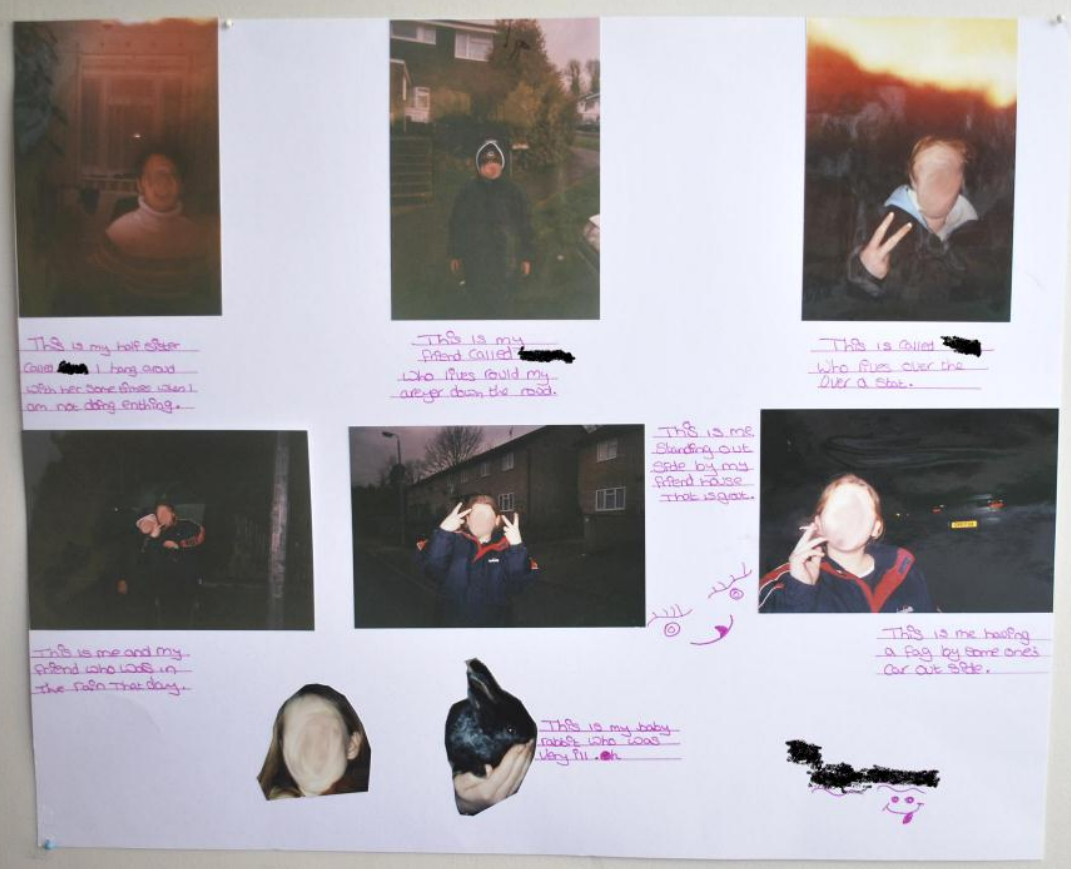


Children's Geographies Paper, final before Proofs

Figure 3 - Lee's Storyboard

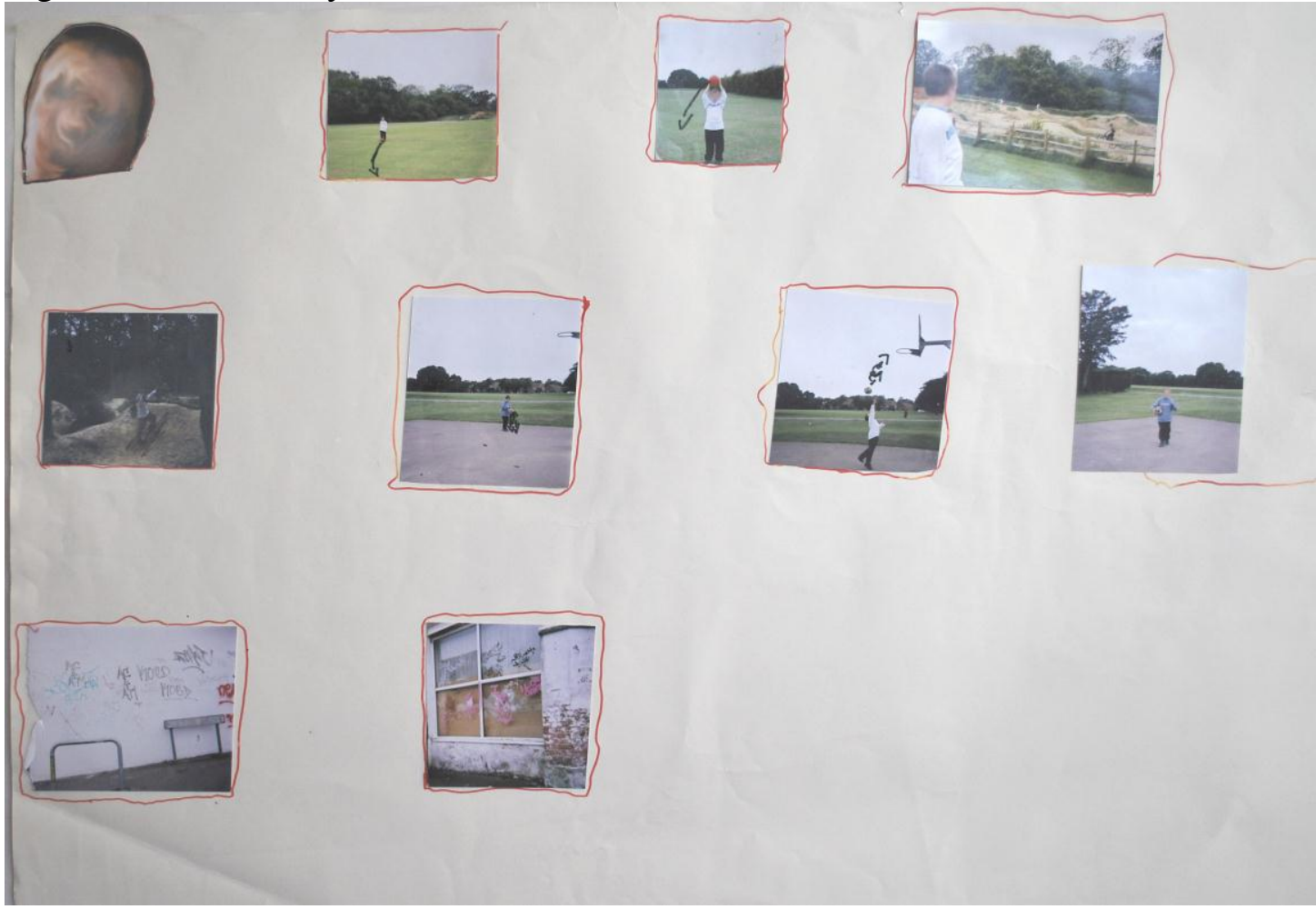




\section{Appendix 1: Research Participants Pseudonyms}

\begin{tabular}{|l|l|}
\hline Aiden & $\begin{array}{l}\text { Boy with specific learning disabilities, white, and social group 7 } \\
\text { (parents employed in routine occupations). }\end{array}$ \\
\hline Amy & $\begin{array}{l}\text { Girl with bodily and socio-emotional differences, white and } \\
\text { undisclosed social group. }\end{array}$ \\
\hline Andrew & $\begin{array}{l}\text { Boy with specific learning disabilities, white and social group 2 } \\
\text { (father employed in lower managerial occupation, mother, full } \\
\text { time carer). }\end{array}$ \\
\hline Annie & $\begin{array}{l}\text { Girl with socio-emotional differences, 'looked after' by social } \\
\text { services. }\end{array}$ \\
\hline Helen & $\begin{array}{l}\text { Girl with bodily differences, not a wheelchair user, white and } \\
\text { social group 7 (parents work in routine occupations) }\end{array}$ \\
\hline Holly & $\begin{array}{l}\text { Girl with bodily differences; a wheelchair user with visual } \\
\text { impairment, white and both parents unemployed. }\end{array}$ \\
\hline Joe & $\begin{array}{l}\text { Boy with socio-emotional differences and specific learning } \\
\text { disabilities, white and social group 6 (mother employed in semi- } \\
\text { routine occupation). }\end{array}$ \\
\hline John & $\begin{array}{l}\text { Boy with socio-emotional differences, white and social group 6 } \\
\text { (parents employed in semi-routine occupations). }\end{array}$ \\
\hline Kevin & $\begin{array}{l}\text { Boy with socio-emotional differences, white and social group 7 } \\
\text { (parents employed in routine occupations). }\end{array}$ \\
\hline Lee & $\begin{array}{l}\text { Boy with socio-emotional differences, white and social group 7 } \\
\text { (parents employed in routine occupations). }\end{array}$ \\
\hline Peter & $\begin{array}{l}\text { Boy with various bodily differences, not a wheelchair user, and } \\
\text { hearing and speech and language differences, white and social } \\
\text { group 7 (parents employed in routine occupations). }\end{array}$ \\
\hline Tom & $\begin{array}{l}\text { Boy with specific learning differences and socio-emotional } \\
\text { differences, white and social group undisclosed. }\end{array}$ \\
\hline $\begin{array}{l}\text { Girl with bodily differences, not a wheelchair user, white and } \\
\text { social group 7 (parents employed in routine occupations). }\end{array}$ \\
\hline
\end{tabular}

\footnotetext{
i The theme of being 'half and half' appears to be fairly pervasive amongst young people, particularly with bodily differences. A young people in Pyer's (2007) research also claimed to be 'half and half'.

ii The Inclusion Centre was a Children's Fund resourced youth worker led initiative that involved taking young people from mainstream lessons for a variable period of time to work in a smaller group. As the teachers emphasised

“...they're not necessarily that close to exclusion or anything like that - they're just, in fact they're probably ones that were trying to re-include...' (Teacher 1) "Yeah, they're excluded in the widest sense of the word for whatever reason. I mean I a couple of them are looked after children aren't they?" (Teacher 2)

${ }^{\text {iii }}$ I use the term anti-school rather than anti-educational norms to express that young people felt disenfranchised by the curricula and institutional practices of schools, despite often being aware of the importance of education.

${ }^{\text {iv }}$ YW indicates Youth Worker. Staff in School 3 insisted on the presence of a Youth Worker in discussion groups given the challenging behaviour presented by some of the young people. Although evidently the presence of another adult raises ethical concerns, youth workers agreed to maintain the confidentiality of the focus group discussions. Further, the relationships between youth workers and young people are generally more egalitarian than those between teachers and young people.
} 